\title{
Dispersal of non-myrmecochorous plants by a "keystone disperser" ant in a Mediterranean habitat reveals asymmetric interdependence
}

\author{
Á. Barroso · F. Amor · X. Cerdá · R. R. Boulay
}

\begin{abstract}
In contrast to other plant-animal mutualisms, seed dispersal interactions, and particularly seed dispersal by ants, are generally considered asymmetric, non-specialized relationships in which dispersers depend less on plants than vice versa. Although myrmecochory is well understood in many terrestrial ecosystems, dispersal of non-elaiosomebearing seeds by ants has barely been studied outside the Neotropics. Aphaenogaster senilis, a common ant in Southern Spain, collects a great variety of non-myrmecochorous diaspores along with insect prey. At our study site, fleshy fruits of Arum italicum, Phillyrea angustifolia and Pistacia lentiscus represent up to one-fourth of the items collected by A. senilis from June to November. However, they are mostly ignored by other ants. In the laboratory, the addition of A. italicum fruits to A. senilis insect-based diet increased male production and both worker and queen pupae size. Seeds were transported up to $8 \mathrm{~m}$ away from the mother plant and deposited in a favorable habitat allowing a relatively high proportion of germination. Given important differences in seed production between species, our data suggest that $A$. senilis removes virtually all seeds of
\end{abstract}

Electronic supplementary material The online version of this article (doi:10.1007/s00040-012-0268-0) contains supplementary material, which is available to authorized users.

Á. Barroso · F. Amor · X. Cerdá

Estación Biológica de Doñana, CSIC, 41092 Seville, Spain

R. R. Boulay

Departamento de Zoología, Universidad de Granada,

18071 Granada, Spain

R. R. Boulay $(\square)$

Institut de Recherche sur la Biologie de l'Insecte UMR CNRS

7261, Université François Rabelais, 37200 Tours, France

e-mail: raphael.boulay@univ-tours.fr
A. italicum, but a negligible fraction of $P$. lentiscus seeds. We conclude that in contrast to the common view, dispersal of non-myrmecochorous Mediterranean plants by ants might be an important phenomenon. Keystone disperser ants like A. senilis probably obtain an important fitness advantage from non-myrmecochorous diaspore collection. However, plant benefit may vary greatly according to the amount of seeds per individual plant and the existence of alternative dispersal agents.

Keywords Fleshy fruits · Arum italicum - Aphaenogaster . Nutrition · Dispersal

\section{Introduction}

Seed dispersal by animals is a popular topic in ecology and evolutionary biology (Snow, 1971; McKey, 1975; Janzen, 1983; Herrera, 1995, 2002). Many fruit and seed consumers have been shown to positively affect plant recruitment and population dynamics, emphasizing the mutualistic nature of this kind of interaction (reviews by Wang and Smith, 2002; Fenner and Thompson, 2004). However, the degree of specialization among partners and influence of current dispersers on the evolution of plant dispersal adaptations are still debated (Wheelwright and Orians, 1982; Herrera, 1995; Jordano, 1995; Alcántara et al., 2007). Several lines of evidence suggest that, in contrast to other highly specialized, tightly coevolved plant-animal mutualisms (e.g. pollination), seed dispersal may consist of asymmetric interactions evolving through diffuse selection. First, dispersal mutualisms involving a single animal species are relatively rare. On the contrary, plants' diaspores attract phylogenetically diverse animal guilds that change over time and space (note that throughout the article we employ 
diaspores as a general term for dispersal units which may be fruits or seeds depending on the plant species). Second, while plants often rely entirely on animals for seed dispersal, the reverse is not necessarily true because animals can feed on a large variety of resources, creating asymmetric partner interdependence. Third, animals can have contrasting qualitative and quantitative effects on seeds including dispersal, predation and exploitative parasitism (i.e. cheating; Horvitz and Schemske, 1986; Bronstein, 1994; Boulay et al., 2007a).

Ants constitute the most abundant animal fauna of many terrestrial habitats. They are also among the main seed dispersers. Studies of seed dispersal by ants have paid much attention to true myrmecochory. Myrmecochory sensu stricto generally refers to the dispersal of seeds bearing a lipid and nutrient-rich elaiosome (Brew et al., 1989; Hughes et al., 1994; Boulay et al., 2006; Fischer et al., 2008; Pfeiffer et al., 2010). This appendage elicits ants to transport the elaiosomebearing diaspores back to their nest. After it has been consumed mostly by the larvae (Fischer et al., 2005), the ants discard the intact seed with other food remains. By transporting the vulnerable seeds soon after their release, ants allow plants to colonize new habitats (Gorb and Gorb, 2003), reduce intraspecific competition and decrease mortality by predation and fire (Heithaus, 1981; Bond and Slingsby, 1984; Hughes and Westoby, 1992; Boulay et al., 2007a, 2009a). However, ant seed dispersal benefits may differ greatly between species (Giladi, 2006). Gove et al., (2007) coined the term "keystone dispersers" for species within an ant community that contribute disproportionately to seed dispersal. On the contrary, it was shown that, locally, many ants behave as cheaters by detaching elaiosomes in situ without transporting the seeds (Zelikova et al., 2008; Ness et al., 2009; Boulay et al. 2007a, b; Aranda-Rickert and Fracchia, 2011).

Ants do not only disperse elaiosome-bearing seeds. Many tropical ants, particularly in the New World, remove the fleshy fruits of bird-dispersed plants (Roberts and Heithaus, 1986; Böhning-Gaese et al., 1999; Pizo and Oliveira, 2000; Christianini et al., 2007; Christianini and Oliveira, 2009, 2010). In Mediterranean scrublands, the role of ants in fleshy fruits dispersal is controversial (Herrera, 2001). The harvester ant Messor minor was suggested to disperse several bird-dispersed plants in a Southern Italy garrigue habitat (Aronne and Wilcock, 1994). However, seed survival and germination after being manipulated by this granivore ant was not tested. Fleshy fruits are transport by Aphaenogaster and Cataglyphis ants in Spain but the importance of this phenomenon is unknown (Traveset, 1994; Hulme, 1997; Bas et al., 2009).

Seed dispersal by ants has long been considered as a typical example of a non-specialized interaction potentially involving many ant species with no feeding specificity
(Beattie and Hughes, 2002). At first glance, food rewards offered by ant-dispersed plants show little morphological and chemical specificity, suggesting that they can attract a large array of omnivorous ants. However, in spite of a few recent studies (e.g. Lubertazzi et al., 2010), the diet of seed disperser ants has not been investigated in great detail, which limits our understanding of their degree of dependence on plants. Moreover, although ant dependence on myrmecochorous seeds has been tested experimentally, the results of independent studies are rather inconsistent. In the field, Morales and Heithaus (1998) showed that increasing the availability of myrmecochorous seeds for Aphaenogaster rudis colonies enhanced queen production, resulting in a less male-biased sex ratio. Further analyses suggested that the observed response was a quantitative effect of adding more food rather than a qualitative effect of elaiosome nutrients (Bono and Heithaus, 2002). Other studies conducted in the laboratory showed an increase of worker but not sexual production in Myrmica ruginodis and M. rubra (Gammans et al., 2005; Fokuhl et al., 2007). In Temnothorax crassispinus it increased female weight and decreased male weight (Fokuhl et al., 2012). Adding Datura elaiosomebearing seeds to a standard diet had no effect on queen survival or brood production in Pogonomyrmex californicus (Marussich, 2006).

To our knowledge, ant dependence on fleshy fruits has not yet been investigated. In the present study, we questioned asymmetric interdependence in mutualisms between ants and non-myrmecochorous plants in a Mediterranean habitat. Our aim was to test the general hypotheses that (1) a limited number of ant species both depend on and provide dispersal service to many non-myrmecochores and (2) the benefit obtained by plants varies between species, depending on crop size (number of seeds or fruits per individual plant). We examined non-myrmecochorous seed use and dispersal by ants in a southern Spain shrub habitat as a model system for testing our hypotheses. The ant Aphaenogaster senilis is a keystone disperser of myrmecochores in Mediterranean habitats across the Iberian Peninsula (Boulay et al., 2007a; 2009a; Espadaler and Gómez, 1997). We assessed the interdependence between $A$. senilis and the diaspores of the most abundant non-myrmecochorous plants in our study habitat by estimating both the proportion and number of fruits and seeds in their diet. We reasoned that A. senilis dependence on plants would be a function of the proportion of diaspores in their diet, while plant dependence on $A$. senilis would be a function of the number of retrieved diaspores compared to species-specific crop size. We also tested experimentally whether diet supplementation with Arum italicum fruits affected larval fate and pupae size in the laboratory. Finally, we compared A. senilis diasporeremoval behavior with that of other ants present in the same 
community and measured seed survival, germination rates and dispersal distances.

\section{Materials and methods}

\section{Study system}

The study was conducted at La Algaida, Doñana Natural Park (Southern Spain; 36 $6^{\circ} 1.467^{\prime} \mathrm{N}, 6^{\circ} 19.295^{\prime} \mathrm{W}, 2 \mathrm{~m}$ elevation). It is located in a Mediterranean region with oceanic influence. Summers are hot and dry, while winters are cool and humid. The study area is a sandy strip located between a pine forest and a marshland. Shrub vegetation is dominated by Pistacia lentiscus (Anacardiaceae) and Phillyrea angustifolia (Oleaceae). Both produce large crops of small bird-dispersed drupes (ESM) that can exceed 10,000 fruits in the case of P. lentiscus (Jordano 1989). They fructify in autumn (October-November). Herbs produce much smaller crop size than shrubs. They include various species of Poaceae and Asteraceae. Arum italicum (Araceae), Ornithogalum orthophyllum (Liliaceae), Juncus acutus (Juncaceae) and Narcissus serotinus (Amaryllidaceae) are also relatively frequent. A. italicum is a perennial shadetolerant herb that grows preferentially below P. lentiscus. Each plant is composed of one to three $30-\mathrm{cm}$ high spadices that produce up to 100 red fleshy fruits that mature in July (Méndez and Díaz, 2001). The fruits contain calcium oxalate crystals, which are toxic for mammals and to our knowledge no legitimate disperser has been described (Herrera, 1989). O. orthophyllum is also a perennial herb that grows in patches. Each $10 \mathrm{~cm}$ stalk produces a few capsules that often lie directly on the ground (ESM). Fructification of O. orthophyllum occurs in March. No myrmecochore is present in the study area, but a few plants of $R$. alaternus grow about $1 \mathrm{~km}$ away.

The ant community is composed of at least 11 species, among which A. senilis, Messor barbarus, Tetramorium forte and Cataglyphis rosenhaueri are the most abundant. A. senilis is a monogynous, monandrous species. Colonies contain an average of 1,300 monomorphic workers that are about $5 \mathrm{~mm}$ long and weight 5-8 mg (Boulay et al., 2007c). At our study site, average nest density is 174 nests ha $^{-1}$ (A. Barroso, unpublished data). This ant is strictly diurnal species and is active from February to November. Colonies frequently relocate nests, depending on environmental constraints. In spring and fall they occupy open areas, while in summer they move into the shade to obtain relief from extreme heat.

Colonies disperse by fission. As a consequence, resources are almost entirely allocated to the production of workers and queen-derived males. Very few queens are produced while the mother queen is present in the colony.
Experimental removal of the mother queen from laboratory colonies stimulates a few totipotent first instar larvae to develop into replacement queens (Boulay et al., 2009b). About 10 days after the queen is removed, workers also start laying haploid eggs that hatch after 30 days and develop into males.

Interdependence between $A$. senilis and non-myrmecochorous diaspores: diet analysis

The proportion and number of diaspores in A. senilis diet were estimated in two steps. First, the proportion of diaspores in the diet was estimated. Foragers carrying items back to the nest were sampled from 57 nests and over 16 sampling days between June 2003 and November 2009. Up to 100 ants were collected at each nest entrance. All food items were kept in $70 \%$ alcohol and identified in the laboratory.

In a second step, the number of loaded workers returning to their nest was recorded. A total of 86 nests were observed over 19 days between April 2004 and November 2009. Each nest was sampled during $10 \mathrm{~min}$ sessions, once every hour, for the duration of their daily foraging activity. Foraging generally lasts $12 \mathrm{~h}$ starting at 8:00 a.m. (Solar Local Time; Caut et al., in press). In order to limit interference caused by observers on ant foraging activity, foragers were not collected. For each nest, the estimated number of retrieved items was then multiplied by the proportion of diaspore in the diet during the same month of the year (obtained from step 1). Between months differences in diaspore proportions and quantities were compared by ANOVA (R Development Core Team, 2010).

\section{A. senilis dependence on A. italicum}

non-myrmecochorous diaspores: diet supplementation

The effect of fruit consumption on A. senilis larval development was investigated in the laboratory. Ten colonies were collected in June 2011 near the study site. They were maintained in the laboratory in $26 \times 17 \times 12 \mathrm{~cm}$ (length $\times$ width $\times$ height) plastic containers, the inner wall of which was coated with Fluon ${ }^{\circledR}$. Colonies were provided one teaspoon of sliced Tenebrio molitor mealworms (approximately $2.5 \mathrm{~g}$ fresh weight) three times a week, and maintained at $28{ }^{\circ} \mathrm{C}$ in darkness. The ants could shelter in four $2 \times 20 \mathrm{~cm}$ test tubes half filled with water maintained with a cotton plug. After 3 months in control conditions, 2 queenless groups of 200 workers and 20 first instar larvae were prepared from each mother colony. Each group was then fed three times a week with either one teaspoon of sliced mealworms (Control; $n=10$ ) or with one teaspoon of sliced mealworms plus two A. italicum fruits (Treatment; $n=10$ ). Therefore, both control and treatment groups received an excess of mealworms in comparison to the 
ration supplied to our stock colonies that contain ca. 1,000 workers and a much larger brood. A. italicum fruit and seed fresh weights measured on a Sartorius $10^{-4} \mathrm{~g}$ precision balance were $0.200 \pm 0.010$ and $0.061 \pm 0.007 \mathrm{~g}$, respectively (mean $\pm \mathrm{SE} ; n=20$ ). So, each treatment group received $0.834 \pm 0.078 \mathrm{~g}$ of pulp per week, which is approximately $14 \%$ of the mealworm ration. The fruits used had been frozen and stored at $-20{ }^{\circ} \mathrm{C}$ just after collection in the field. The production of worker, queen and male pupae was checked three times a week during the 3 months of the experiment. Pupae length was then measured on a Leica ${ }^{\circledR}$ stereomicroscope equipped with a digital camera. Worker mortality rate (percentage of death day ${ }^{-1}$ ) was estimated by counting the number of living workers after 42 and 84 days and averaging mortality rates over both periods. Linear mixed models were used to test differences in the production and size of worker, queen and male and in worker mortality rates. The colony of origin was included as a random factor, while diet was a fixed factor. Holm's sequential Bonferroni procedure was used to control for the risk of accepting false negatives ( $\mathrm{R}$ Development Core Team, 2010).

Dependence of plants on A. senilis: relative specificity of diaspore-removal behavior

The relative importance of diaspore removal by ants versus vertebrates was tested in three field experiments for four plant fruits (A. italicum, $P$. angustifolia, P. lentiscus and $O$. orthophyllum) during their respective period of fructification. These four species were chosen because they were among the most abundant in the diet of A. senilis (see Results).

The first experiment compared fruit removal by ants and other animals. Fruit depots of A. italicum, $P$. angustifolia and $P$. lentiscus were set up on the ground during their respective fructification periods. At 8:00 a.m., 15 pairs of depots containing 10 fruits each were set up near the plants. One depot of each pair was open to all animals, while the other was covered with a wire mesh. The size of the mesh $(1 \mathrm{~cm})$ allowed the passage of invertebrates, including ants, but not that of vertebrates like mice. Preliminary observations indicated that in contrast the other plants, the fruit of O. orthophyllum remained attached to the plant. Ants were observed cutting the peduncle of the fruit and the stalk in order to remove the fruit. For that reason, we chose to adapt the procedure for this plant species and offer the seeds in less artificial conditions. We selected 15 pairs of plants, counted the number of capsules at 8:00 a.m. and covered half of them with a vertebrate excluder. The other half remained accessible to all animals. Non-removed diaspores were counted after $24 \mathrm{~h}$. Linear mixed models were used to compare diaspore removal between control (open) and experimental (vertebrate excluder) depots, with the pair considered as a random factor. Plant species and vertebrate excluder were fixed factors. The lme function from the $\mathrm{R}$ software was used to fit linear mixed models (R Development Core Team, 2010).

The second experiment compared diaspore removal of A. italicum, $P$. lentiscus, $P$. angustifolia and $O$. orthophyllum by diurnal invertebrates, particularly ants. This experiment was conducted during the period of fructification of each plant species. Depending on the plant species, 15 or 30 observation stations were observed. These stations were set up between 8:00 and 10:00 a.m., close to fruiting plants. Each station was composed of a $60 \times 60 \mathrm{~cm}$ quadrat at the center of which 5-20 fruits were deposited, depending on the plant species. Ant presence and behavior were recorded in the quadrats during 3 min every hour until 8:00 p.m. or until the fruits had been removed. Ant behavior was classified as (1) ignore, (2) antennate, explore or feed on the pulp and (3) remove diaspore. For each plant species, the frequency of each behavioral category was compared between ant species by means of Pearson $\chi^{2}$ test (R Development Core Team, 2010). In addition, linear mixed models were fitted for each plant species with removal rate per hour as the response variable and the occurrence of each ant species in the quadrat during the previous hour as explanatory variable. The quadrats were included as random variables.

A third experiment estimated the fruit removal rate of A. italicum by nocturnal animals. Before sun set (9:00 p.m.) we used small wooden sticks to mark the exact position of each fruit located below 15 plants with a. After sunrise, at 8:00 a.m. the following day, we recorded whether the fruits were still at the same location. This experiment was repeated on three consecutive nights during the fruiting period of A. italicum (8, 9 and 10 July 2009).

Dependence of plants on A. senilis: dispersal distance, seed survival and germination

Field and laboratory data were collected to determine how A. senilis affects diaspore fate during and after dispersal. Distance of diaspore dispersal by A. senilis was estimated for A. italicum only. Thirty plants were monitored during periods of $3 \mathrm{~min} \mathrm{~h}^{-1}$ during $12 \mathrm{~h}$. When A. senilis workers were observed removing fruits, they were followed to their nest entrance and the plant-nest distance was measured. The nest day an area represented by a $2 \mathrm{~m}$ radius quarter-circle centered on the nest was carefully checked during approximately $1 \mathrm{~h}$ to locate rejected A. italicum seeds.

Seeds of A. italicum, P. lentiscus, $P$. angustifolia and $O$. orthophyllum were collected after they had been rejected in the vicinity of the nests $(<1 \mathrm{~m})$. They were brought to the lab and moistened in water for $24 \mathrm{~h}$. They were then cut longitudinally and placed in a $1 \%$ Tetrazolium (TZ) water 
solution for $24 \mathrm{~h}$. This treatment results in live (respirating) embryos being stained red (Grooms, 2006), which were subsequently the seeds that we classified, and counted, as survivors. Pearson $\chi^{2}$ test was used to compare seed survival between plant species.

Two germination tests were conducted using freshly collected A. italicum seeds. The aim of these experiments was to test whether pulp removal by ants affected seed germination. First, 50 seeds were collected outside A. senilis nests $(<1 \mathrm{~m}$; dispersed) and 50 seeds were collected from plants (non-dispersed). These were sowed individually in peat pots that were maintained in a green house at $25^{\circ} \mathrm{C}$. Water was provided every $2-3$ days. The proportion of germinated seeds in both groups was checked after 20 weeks and compared using Yates-corrected $\chi^{2}$ test. A second experiment was conducted in the field using seeds collected in August 2009. Sixteen pockets prepared with a mosquito net were filled each with 12 ant-dispersed seeds collected at the nest entrance. Six other pockets were filled with six non-dispersed seeds extracted from matured fruits collected on the plants (all the fruit pulp was carefully washed out). The seeds were sowed in what is typically a favorable habitat, i.e., below established $P$. lentiscus shrubs, in September 2009. Germination was checked after 27 weeks. The proportion of germinated seeds per envelope was compared between treatments by ANOVA (R Development Core Team, 2010).

\section{Results}

Interdependence between $A$. senilis and non-myrmecochorous diaspores: diet analysis

A total of 2,148 retrieved food items were sampled, out of which $334(16 \%)$ were seeds or fruits. The remaining were mostly insect corpses, flower petals and bird feces. The proportion of diaspores in the diet was close to zero from February to May but increased significantly in the second part of the year (difference between months: ANOVA: $\left.F_{9,47}=6.13, P<0.0001\right)$. In October diaspores represented $46 \pm 10 \%$ (mean \pm SE) of all retrieved food items. Fruits of A. italicum, $P$. lentiscus and $P$. angustifolia were among the preferred diaspores. In July, fruits of A. italicum accounted for almost one-fourth of the retrieved items (22 $\pm 9 \%$, Fig. 1a). In autumn, the fruits of A. italicum were no longer available and the ants switched to those of $P$. lentiscus and $P$. angustifolia. In October, the fruits of both plants accounted for a major fraction of the diet of A. senilis ( $12 \pm 8$ and $25 \pm 13 \%$, respectively). Other seeds and fruits retrieved in lesser proportions included those of $J$. acutus (Juncaceae), $N$. serotinus (Amaryllidaceae),
Rhamnus alaternus (Rhamnaceae), Anagallis sp. (Primulaceae), Erodium sp. (Geraniaceae), Medicago sp. (Fabaceae), Frankenia laevis (Frankeniaceae) and various species of unidentified Poaceae and Asteraceae.

The foraging activity of $A$. senilis showed a marked annual pattern. The number of retrieved food items was the highest in May, ranging between 336 and 1,242 item$\mathrm{s}$ nest $^{-1} \mathrm{day}^{-1}$, and the lowest in November, ranging between 6 and 96 items nest ${ }^{-1}$ day $^{-1}$. The combination of the number and proportion of items retrieved per day and nest indicated that the estimated number of retrieved diaspores increased significantly between June and November compared to the previous months (Fig. 1b; ANOVA: $\left.F_{9,76}=11.58, P<0.0001\right)$. In June, colonies of A. senilis retrieved up to $37.9 \pm 8.3$ (mean $\pm \mathrm{SE}$ ) fruits of A. italicum per day and in October they collected $16.0 \pm 2.6$ and $32.3 \pm 5.4$ fruits of P. lentiscus and $P$. angustifolia, respectively.
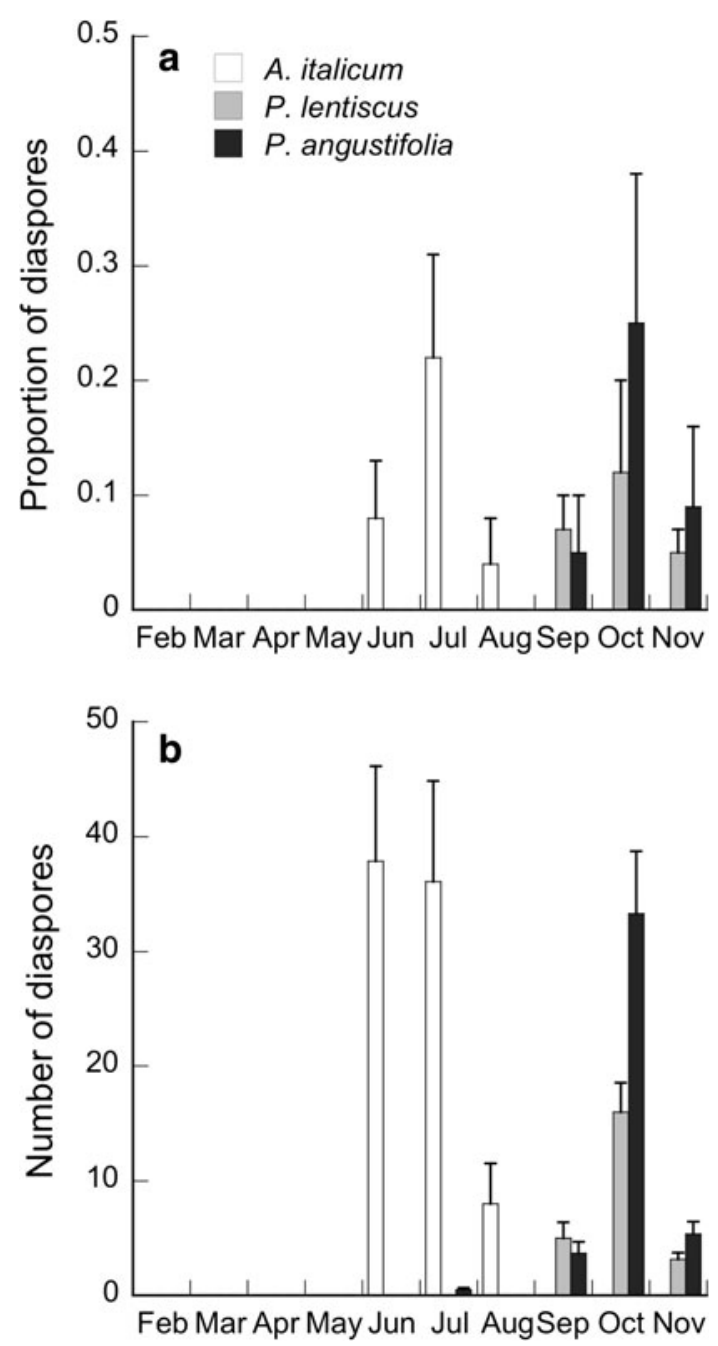

Fig. 1 Annual variations in the proportion (a) and number (b) of diaspores in the diet of $A$. senilis. Values are mean $\pm \mathrm{SE}$ 
A. senilis dependence on $A$. italicum

non-myrmecochorous diaspores: diet supplementation

The addition of A. italicum fruits to a normal mealworm-based diet had two major consequences. It increased diploid larvae size and the number of workers produced males. Although the number of first instar diploid larvae developing into workers and queens did not differ significantly between the two diets, both female castes were significantly larger when A. italicum fruits were provided (Table 1). Queen and worker pupae were 10 and $9 \%$ longer when $A$. italicum fruits were provided.

Only five male pupae were produced in total during the first 3 weeks of the experiment. Since orphan workers begin producing male egg after about 10 days, these males were in all likelihood male offspring of the removed queens. These males were removed from the analysis. Workers' male offspring pupae first appeared after 50 days. They were 2.1 times more numerous when A. italicum fruits were provided (Table 1). Males were only $2 \%$ longer with $A$. italicum fruits, which was not significantly different. On average, $1.39 \pm 0.07$ workers died every day in both treatments, which represented a mortality rate of $0.94 \pm 0.10 \%$ dead workers day ${ }^{-1}$. Mortality rate did not differ according to the diet.

Dependence of plants on A. senilis: relative specificity of diaspore-removal behavior

The proportion of seeds removed in $24 \mathrm{~h}$ differed significantly between plant species (lme: $\left.F_{3,59}=12.79, P<0001\right)$. A. itali-

Table 1 Effect of diet supplementation with A. italicum fruits on the number and size of worker, male and queen pupae and worker survival rate

\begin{tabular}{|c|c|c|c|c|c|}
\hline & MW & $\mathrm{MW} / \mathrm{Ar}$ & $\begin{array}{l}d f \\
\text { (num, } \\
\text { den) }\end{array}$ & $F$ & $P$ \\
\hline $\begin{array}{l}\text { Number of new } \\
\text { queens }\end{array}$ & $3.4 \pm 0.37$ & $2.5 \pm 0.52$ & 1,9 & 2.93 & 0.1212 \\
\hline $\begin{array}{l}\text { Number of new } \\
\text { workers }\end{array}$ & $9.4 \pm 1.49$ & $11.2 \pm 1.22$ & 1,9 & 3.57 & 0.0913 \\
\hline $\begin{array}{l}\text { Number of } \\
\text { workers' male } \\
\text { offspring }\end{array}$ & $2.8 \pm 1.06$ & $6.0 \pm 1.17$ & 1,9 & 11.29 & 0.0084 \\
\hline Queen size (mm) & $5.21 \pm 0.07$ & $5.74 \pm 0.11$ & 1,44 & 20.70 & 0.0001 \\
\hline $\begin{array}{l}\text { Worker size } \\
(\mathrm{mm})\end{array}$ & $4.18 \pm 0.05$ & $4.57 \pm 0.05$ & 1,136 & 57.23 & 0.0001 \\
\hline Male size $(\mathrm{mm})$ & $4.35 \pm 0.04$ & $4.44 \pm 0.05$ & 1,44 & 3.02 & 0.0891 \\
\hline $\begin{array}{l}\text { Worker mortality } \\
\text { rate }(\% \text { of } \\
\left.\text { death day }{ }^{-1}\right)\end{array}$ & $1.01 \pm 0.07$ & $0.97 \pm 0.07$ & 1,9 & 0.09 & 0.7669 \\
\hline
\end{tabular}

All values are mean \pm SE. Bold values denote significant differences after Holms' sequential Bonferroni correction. $N=10$ groups per diet $M W$ mealworm diet, $M W / A r$ mealworm diet supplemented with A. italicum fruits
Table 2 Percentages of removed diaspores after $24 \mathrm{~h}$ (mean \pm SE) with and without vertebrate excluders

\begin{tabular}{lll}
\hline & Open depots & With vertebrate excluder \\
\hline A. italicum (a) & $0.97 \pm 0.02$ & $0.99 \pm 0.01$ \\
O. orthophyllum (b) & $0.46 \pm 0.12$ & $0.41 \pm 0.12$ \\
P. angustifolia (a) & $0.85 \pm 0.08$ & $0.83 \pm 0.07$ \\
P. lentiscus (b) & $0.49 \pm 0.11$ & $0.58 \pm 0.11$ \\
\hline
\end{tabular}

Different letters between parentheses denote significant differences between plant species. There was no significant difference between open and vertebrate-excluded depots. $N=15$ depots per species and treatment

cum and $P$. angustifolia were the most rapidly removed fruits, while the removal rates of both $P$. lentiscus and $O$. orthophyllum were lower. The vertebrate excluder did not significantly affect removal rate (Table 2 ; lme: $F_{1,59}=0.04, P=$ $0.84)$, nor did the vertebrate excluder effect interact significantly with that of plant species (lme: $F_{3,59}=0.33, P<0.80$ ). This suggests that once they are on the ground, diaspores of the four plant species are mostly removed by invertebrates and that vertebrates have little or no impact on removal.

A total of seven ant species were observed around the studied plants. A. senilis (Asen) and Tetramorium fortis (Tfor) were active from February to November and were frequently observed in the sampling quadrats near the fruiting plants. By contrast, Cataglyphis rosenhaueri (Cros) and Crematogaster auberti (Caub) were only active in summer, during the fructification of $A$. italicum. The frequency of diaspore-removal behavior was extremely biased toward A. senilis. With the exception of $M$. barbarus (Mbar), that was seen transporting one drupe of $P$. angustifolia and one drupe of $P$. lentiscus, $A$. senilis was the only species that removed diaspores (Fig. 2). The other ant species either ignored them or explored them with their antenna. The proportion of removal behaviors by A. senilis versus both of the other behavioral classes (ignore and explore) did not vary significantly between plant species $\left(\chi^{2}=3.83\right.$, $d f=3, P=0.2803)$. No other interaction between diaspores and other diurnal invertebrates was recorded except for one coleopteran that was observed eating an A. italicum fruit.

These results were corroborated by the fact that the proportion of removed diaspores in $1 \mathrm{~h}$ correlated significantly with the occurrence of $A$. senilis during the previous hour, but not with that of other ant species (Fig. 3; Table 3).

Out of 225 fruits of A. italicum localized below the 15 plants before sunset, only $6(2.7 \%)$ were removed by nocturnal animals.

Dependence of plants on A. senilis: seed dispersal, survival and germination

Of the 30 plants that were monitored, 28 were visited by one to three $A$. senilis colonies. The majority of seeds (41\%) 
Fig. 2 Relative frequency of behavioral interactions between the most abundant ant species and the diaspores of four plant species. White ignore, light grey antennate/explore, dark grey remove. Ant species: Asen Aphaenogaster senilis, Tfor Tetramorium forte, Caub Crematogaster auberti, Cros Cataglyphis rosenhaueri, Tnig Tapinoma nigerrimum, $\mathrm{Cscu}$ Crematogaster scutellaris, Mbar Messor barbarus
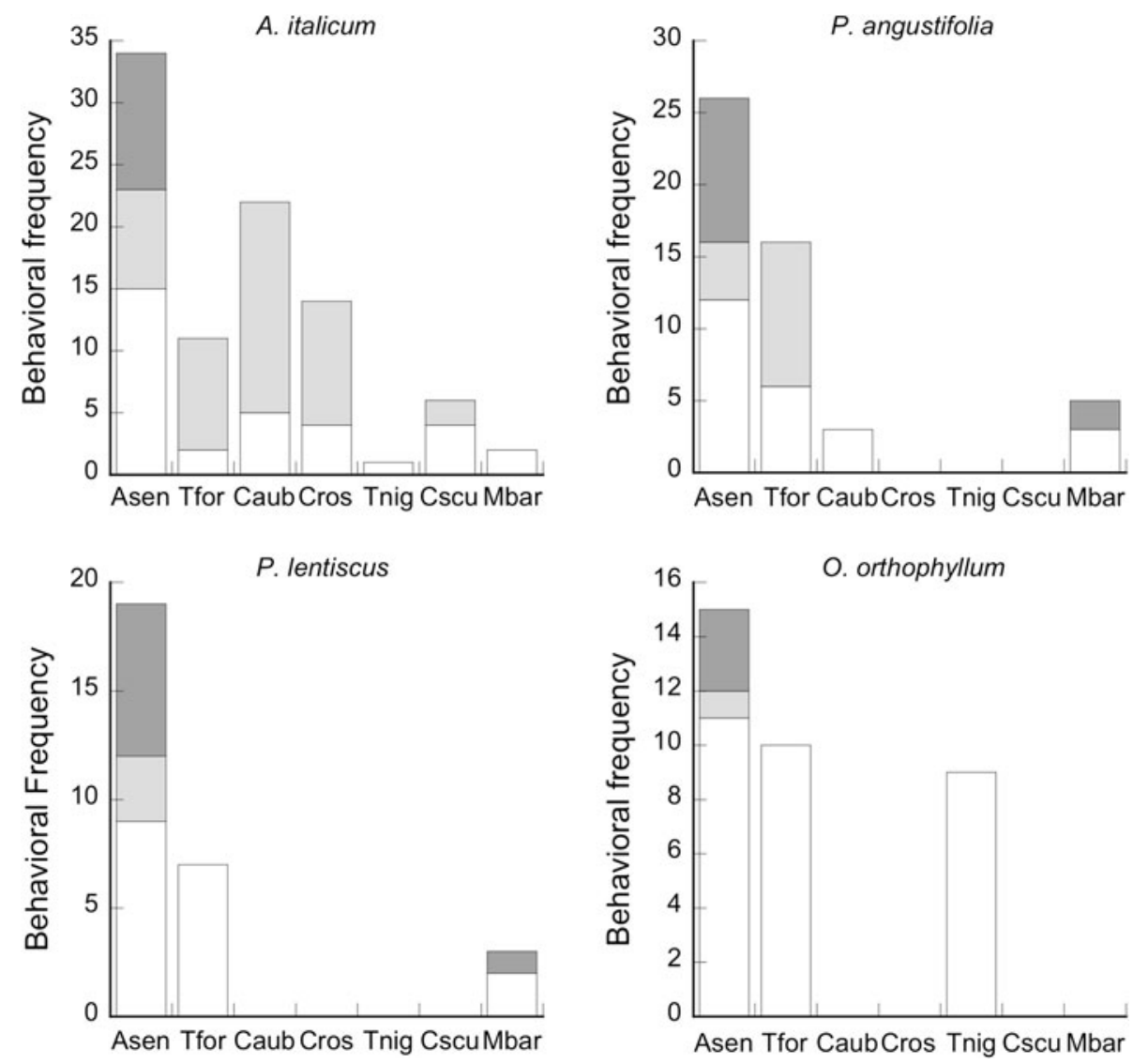

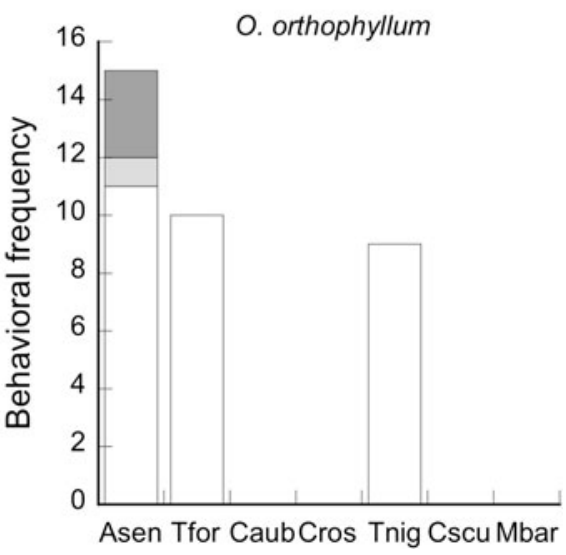

were first moved to a nest located 2-4 m away from the mother plant (Fig. 4) with a few seeds transported as far as $8 \mathrm{~m}$. A second movement occurred after the ants had consumed the fruit pulp. A total of 399 A. italicum seeds were discovered after they had been discarded from ant nests. Most seeds (48\%) were discarded between 25 and $50 \mathrm{~cm}$ away from the nest entrances (Fig. 4).

The Tetrazolium testing indicated that $92 \%(n=26$ seeds) of A. italicum seeds rejected by A. senilis were still alive. This percentage was similarly high, and not significantly different, for the other plant species, P. lentiscus $(80 \%$, $n=10)$, $P$. angustifolia $(96 \%, n=28)$ and $O$. orthophyllum $\left(100 \%, n=37 ; \chi^{2}=8, d f=6, P=0.2381\right)$.

Germination tests gave contrasting results in the lab and in the field. After 20 weeks in laboratory conditions, non-dispersed A. italicum seeds germinated in a significantly higher proportion than dispersed seeds $\left(88 \%\right.$ vs. $68 \%$; Yates-corrected $\chi^{2}=4.72 ; d f=1$; $P=0.029 ; n=50$ seeds per treatment). However, after 27 weeks, the average proportion of seeds that germinated per pocket in the field was not significantly different between dispersed and non-dispersed seeds $(51 \pm 21$ vs. $39 \pm 7 \%$, mean $\pm \mathrm{SE}$, respectively; ANOVA: $\left.F_{1,21}=1.05, P=0.3186\right)$.

\section{Discussion}

This study demonstrates the complexity and variable degree of interdependence asymmetry in ant-seed dispersal interactions. As hypothesized, detailed diet analysis showed that, depending on the season, non-myrmecochorous diaspores may account for a relatively high proportion of the food items retrieved by A. senilis, emphasizing their importance for ants. Moreover, the supplementation of a normal mealworm-based diet with A. italicum fruits enhanced the number of produced males and the size of workers and queens. A. senilis was found to be the primary disperser of A. italicum and $O$. orthophyllum and to remove a high proportion of the fallen fruits of $P$. lentiscus and P. angustifolia, which directly supports our second hypothesis. In our study site, seeds were moved several meters away from the mother plant, and a high proportion survived and germinated. However, the estimated number of removed fruits per nest was low and suggested that, depending on the plant species, ants could either retrieve virtually the entire fruit crop of an individual plant or only a negligible portion.

Seed dispersal by ants has mostly been studied from the plant perspective by determining the potential effect of ants on plant demography and reproduction. Yet, understanding 
Fig. 3 Relation between the occurrence of $A$. senilis in the quadrats (dashed line) and diaspore-removal rate during the following hour (plain line). Values are mean $\pm \mathrm{SE}$
Table 3 Results of the four linear mixed models testing the relation between the occurrence of ant species in a quadrat and diaspore-removal rate during the following hour

Results in bold denote significant correlation between species occurrence and removal rate
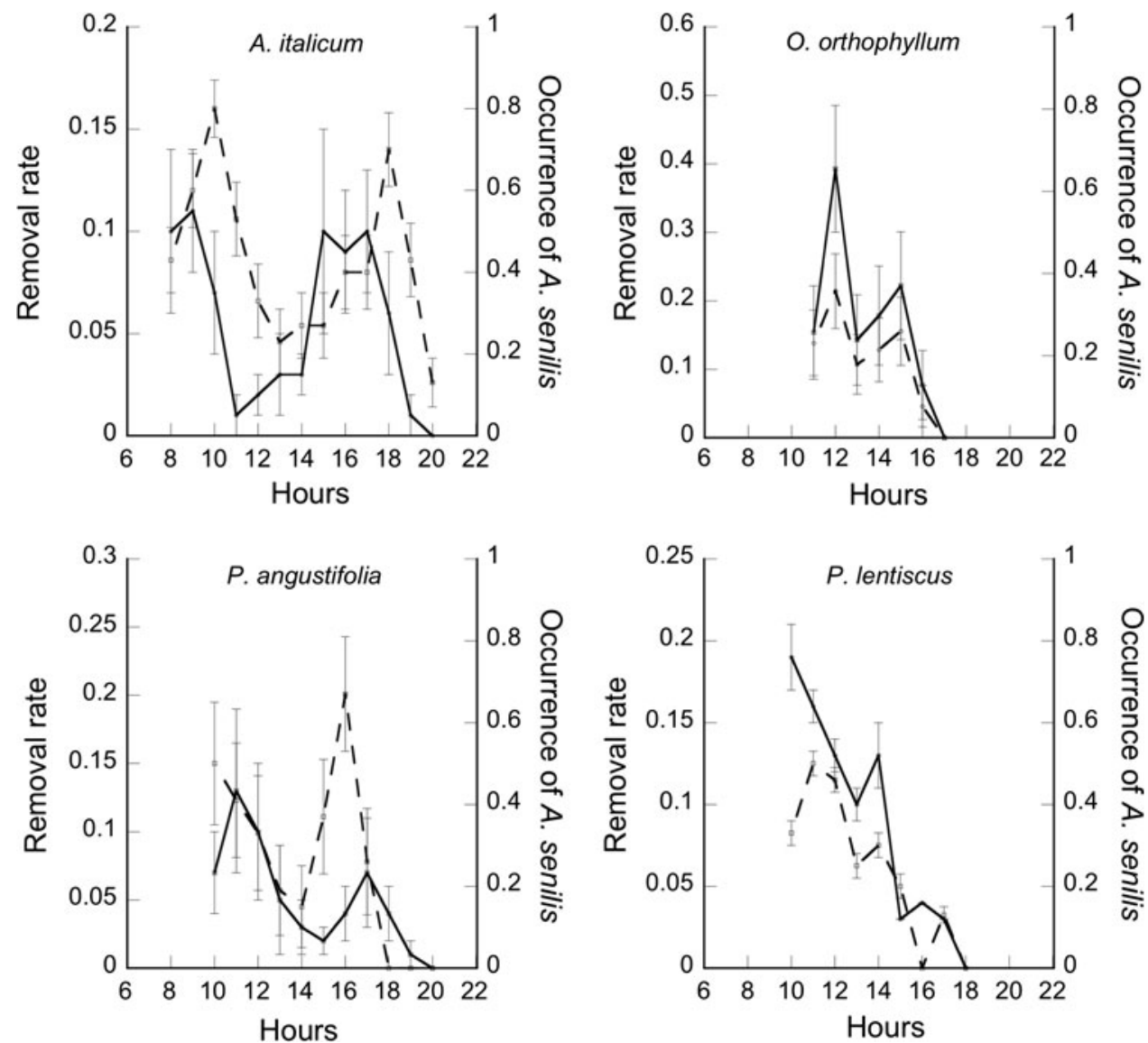

the evolution of seed dispersal by ants also requires insight into the effect of plant rewards on ants. The diet of ants that are keystone seed dispersers is only known for a few species (Lubertazzi et al., 2010). At our study site A. senilis collected a large array of food items, which confirms their omnivorous regime. Particularly interesting are the relative importance and diversity of diaspores included in their diet. In summer and fall, fruits represented up to $1 / 4$ of the retrieved items. These diaspores belonged to at least 12 plant families. The fruits of A. italicum and of P. lentiscus and $P$. angustifolia were $A$. senilis' preferred diaspores in summer and autumn, respectively. A few seeds of Rhamnus alaternus were also collected, although this species does not grow in our study plot. This suggests that these seeds had been removed from bird droppings, as has been shown in other regions (Aronne and Wilcock, 1994; Bas et al., 2009).

Pistacia lentiscus and P. angustifolia are known to be dispersed by birds (Jordano, 1989). The lack of difference in seed removal between open and vertebrate-excluded depots suggests that, during our study, birds or other vertebrates did not remove the fallen fruits of either. To our knowledge, no legitimate disperser had been described for A. italicum and $O$. orthophyllum. The fact that fruit removal rate was not affected by the presence of a wire mesh indicates that vertebrates are not involved in both plants dispersal. Field observations further showed that during the day, the fruits 

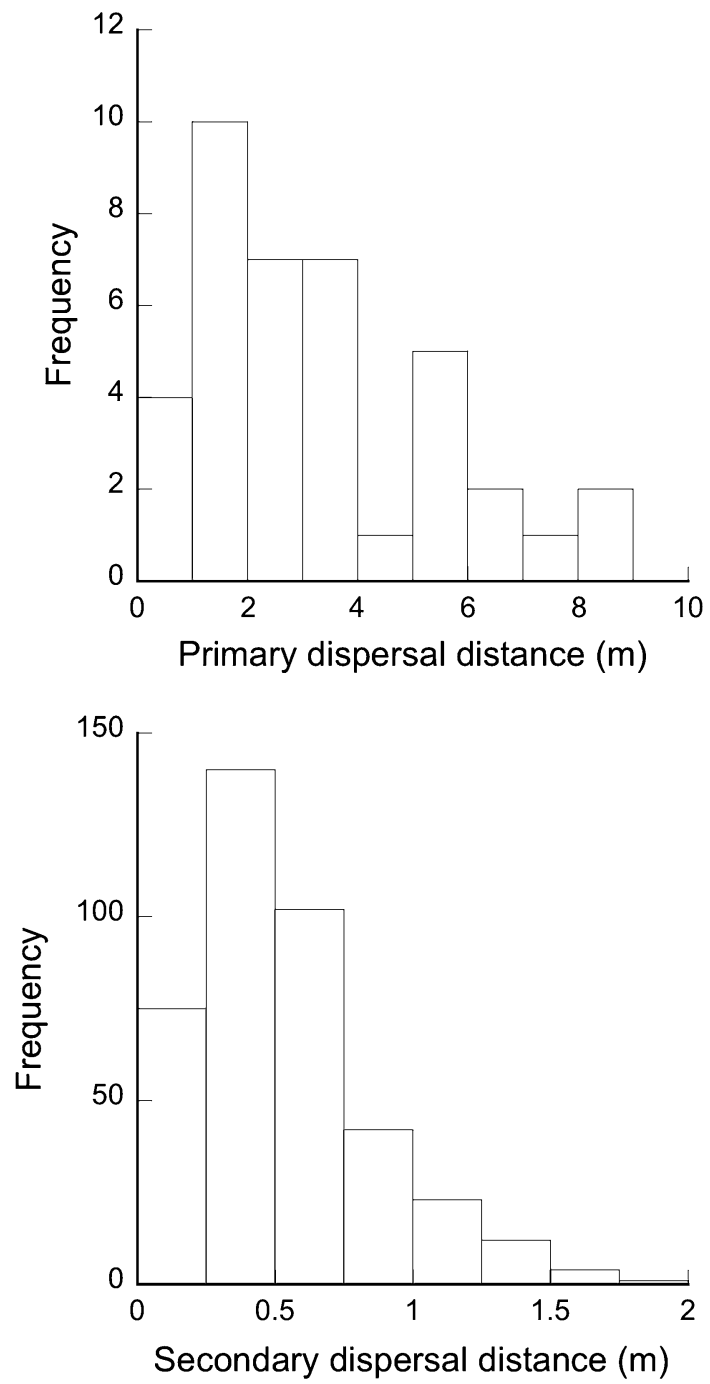

Fig. 4 Distribution of primary and secondary dispersal distances of A. italicum fruits. Primary dispersal is from the plant to the nest. Secondary dispersal is from the nest to the final rejection location

were mostly removed by A. senilis. During the night removal of $A$. italicum by nocturnal animals (such as slugs or snails) is very low (2.7\%). This suggests that $A$. senilis is the main disperser of A. italicum and $O$. orthophyllum. The fruits of A. italicum are toxic to mammals but not to A. senilis, which intensively removed them. In the laboratory, the pulp was consumed both by the workers and the larvae (personal observation).

The effect of adding A. italicum diaspores to an ad libitum insect-based diet produced different effects than those reported with elaiosome-bearing seeds (Gammans et al., 2005; Fokuhl et al., 2007, 2012). Arum italicum fruits did not alter orphan worker survival but increased the number of their sons and thus their inclusive fitness. The absence of the queen does not represent a hopeless reproductive situation for A. senilis because workers can lay their own haploid male eggs and raise their sister larvae into replacement queens (Boulay et al., 2009b). Increasing male production by workers clearly enhances their direct fitness. Moreover, increasing both worker and queen pupae size probably increases their chance of success, and indirectly the whole colony fitness.

The mechanism by which the consumption of A. italicum fruits alters worker reproduction and larval growth is beyond the scope of the present study. However, this effect is probably qualitative rather than quantitative, since mealworms were provided in large excess to treatment and control groups. The pulp of A. italicum contains a high concentration of carbohydrates and carotenoids (Debussche et al., 1987) and possibly many other nutrients that might affect larval development and worker egg-laying. In addition, the consumption of A. italicum pulp by adult workers might affect their physiology and behavior, and indirectly the way nurses rear the brood. The observed effect may also not be specific of A. italicum; providing the fruits of other plant species may have yield similar consequences on ants. Moreover, our result may be amplified by the fact that our laboratory colonies have only access to mealworms. Although mealworms constitute a preferred food item compared to plants, recent studies have shown that this omnivorous ant relies on both plant and arthropod food items (Caut et al., in press). Further studies are necessary to test these hypotheses.

Although the offered fruits potentially attracted several ant species, most behaved as cheaters by feeding on the pulp without contributing effectively to dispersal. A. senilis was almost the only species that removed diaspores. The genus Aphaenogaster, including A. senilis, is known to be an important myrmecochore partner (Hughes et al., 1994; Boulay et al., 2005; Manzaneda et al., 2007; Boulay et al., 2007a, b; Espadaler and Gómez, 1996; Zelikova et al., 2008; Ness et al., 2009). These results cast doubts on the hypothesis that seed dispersal by ants is an unspecialized interaction. They also contradict the hypothesis according to which the main myrmecochorous seed dispersers are scavengers that rarely collect plant material other than elaiosomes (Hughes et al., 1994).

At least two non-exclusive hypotheses may explain the predominant role of Aphaenogaster species in fruit and seed removal. First, as suggested by Boulay et al. (2007a), Aphaenogaster are generally subordinate species that are very quick to discover food items. Conversely, these ants are not efficient at defending food against small, mass recruiting dominant species like Tetramorium forte or Tapinoma nigerrimum. They may therefore prefer to remove food items rapidly to their nest to consume them away from the threat of competitors. A second hypothesis is that, unlike other species (e.g. Tapinoma nigerrimum, Cataglyphis rosenhaueri, etc.) in which foragers fill their crop with liquid food in situ in order to regurgitate it to their 
larvae once in the nest (Eisner, 1957), Aphaenogaster workers are not capable of trophallaxis. Instead, they have to transport solid food items to the nest and then bring the larvae onto these items. In our lab experiment, we observed larvae feeding directly on the pulp of A. italicum although this could not be quantified. Interestingly, in the tropics, Ponerine ants are among the main secondary dispersers of fleshy fruits (Pizo and Oliveira, 1998; Fourcassié and Oliveira, 2002; Passos and Oliveira, 2004). Like Aphae nogaster, these species are not dominant and do not perform trophallaxis.

The benefit for plants of seed dispersal by ants depends on post-dispersal seed fate and on the number of seeds that are removed compared to annual crop size. Survival of antdispersed seeds was relatively high for the four plant species. Germination tests conducted on A. italicum resulted in a significantly lower germination rate of dispersed than nondispersed seeds in the laboratory but not in the field. This apparent discrepancy between field and laboratory results is difficult to explain and should be taken carefully, given the small sample size of non-dispersed seeds in the field. The presence of more pulp remaining on the dispersed seeds used in the field may have enhanced germination, thus reducing the difference with non-dispersed seeds. Although both tests suggested a lower germination rate for dispersed seeds of A. italicum, this rate was still relatively high $(39 \pm 7 \%)$. Such limited negative effect on germination rate may be compensated by advantages related to dispersal distance and deposition site. Primary dispersal allowed transporting most A. italicum fruits an average of 2-4 m away from the mother plant. This corresponds to the average foraging distance of $A$. senilis (Cerdá et al., 2009). This dispersal distance may be sufficient to promote the colonization of new habitats for small herbs like A. italicum but might not be relevant for shrubs whose fruits can be transported a $100 \mathrm{~m}$ by birds (Traveset, 1994; Hulme, 1997). After they consumed the pulp, A. senilis scattered the seeds up to $2 \mathrm{~m}$ from their nest, which probably contributes to reduce intraspecific competition compared to non-dispersed seeds that remain clustered below the mother plant. Moreover, at our study site, A. italicum only grows in the shade of shrubs separated by low-vegetation gaps of only a few meters. A. senilis, which in summer also nests in the shade of shrubs, may allow seeds to cross these gaps to reach favorable habitats. Seeds rejected in the vicinity of the nest may also obtain nutrients favorable to their growth, as has been suggested for several myrmecochores (Manzaneda and Rey, 2012). However this hypothesis should be more rigorously tested.

From the ant perspective, the proportion of seeds in the diet was relatively high during the second half of the year. However, at that time ant foraging activity decreased dramatically and the absolute number of collected diaspores did not exceed 40 per day. This means that foragers from one nest could virtually remove all the fruits of a single spadix (up to 100; Méndez and Díaz, 2001) in $<3$ days. By contrast, for shrubs like $P$. lentiscus, ant impact may be negligible. Given a rough crop size estimate of 10,000 fruits per adult plant (Jordano, 1989), each colony of A. senilis is likely to remove at most $0.16 \%$ of a plant crop per day.

To conclude, we have shown that dispersal of non-myrmecochorous plants by ants in Mediterranean habitats is an underappreciated phenomenon. Fleshy fruits are an important component of some ants' diet, but their contribution to seed dispersal may vary between plant species, depending on crop size. This emphasizes the variable degree of asymmetry in the interdependence between ants and plants. More generally, our results suggest that although plant rewards are apparently non-specific and could potentially attract a large variety of consumers, a few partners have a decisive impact on seed fate.

Acknowledgments We are grateful to Ana Carvajal for assistance in the laboratory and Dr Marcos Méndez for information on the biology of Arum italicum. Jacqueline Minett helped editing English. We are also grateful to Dr Elena Angulo, Prof Johan Billen and two anonymous reviewers for greatly improving the manuscript. This work was funded by MICINN and FEDER (projects CGL2009-12472 to RB and CGL2009-09690 to XC) and MICINN (project CONSOLIDERMONTES CSD2008-00040 to RB and XC); AB thanks the Consejería de Educación (Junta de Andalucía) for work leave. We thank the authorities of Doñana Natural Park for providing permits and facilities to conduct this study. All experiments comply with current Spanish legislation.

\section{References}

Alcántara J.M., Rey P.J., Manzaneda A.J., Boulay R., Ramírez J.M. and Fedriani J.M. 2007. Geographic variation in the adaptive landscape for seed size at dispersal in the myrmecochorous Helleborus foetidus. Evol. Ecol. 21: 411-430

Aranda-Rickert A. and Fracchia S. 2011. Pogonomyrmex cunicularius as the keystone disperser of elaiosome-bearing Jatropha excisa seeds in semi-arid Argentina. Entomol. Exp. Appl. 139: 91-102

Aronne G. and Wilcock C.C. 1994. First evidence of myrmecochory in fleshy fruited shrubs of the Mediterranean region. New Phytol. 127: 781-788

Bas J.M., Oliveras J. and Gomez C. 2009. Myrmecochory and shortterm seed fate in Rhamnus alaternus: ant species and seed characteristics. Acta Oecol. 35: 380-384

Beattie A. and Hughes L. 2002. Ant-plant interactions. In: Plant Animal Interactions (Herrera C.M. and Pellmyr O., Eds). Blackwell Science, Oxford. pp 221-235

Böhning-Gaese K., Gaese B. and Rabemanantsoa S.B. 1999. Importance of primary and secondary seed dispersal in the malagasy tree Commiphora guillaumini. Ecology 80: 821-832

Bond W.J. and Slingsby P. 1984. Collapse of an ant-plant mutualism: the Argentine ant (Iridomyrmex humilis) and myrmecochorous Proteaceae. Ecology 65: 1031-1037

Bono J.M. and Heithaus E.R. 2002. Sex ratios and the distribution of elaiosomes in colonies of the ant, Aphaenogaster rudis. Insect. Soc. 49: $320-325$ 
Boulay R., Fedriani J.M., Manzaneda A.J. and Cerdá X. 2005. Indirect effects of alternative food resources in an ant-plant interaction. Oecologia 144: 72-79

Boulay R., Coll-Toledano J. and Cerdá X. 2006. Geographic variations in Helleborus foetidus elaiosome lipid composition: implications for dispersal by ants Chemoecology 16: 1-7

Boulay R., Carro F., Soriguer R. and Cerdá X. 2007a. Synchrony between fruit maturation and effective disperser's foraging activity increases seed protection against seed predators. Proc. R. Soc. B 274: 2515-2522

Boulay R., Coll-Toledano J., Manzaneda J.A. and Cerdá X. 2007b. Geographic variations in seed-dispersal by ants: are plant and seed traits decisive? Naturwissenschaften 94: 242-246

Boulay R., Hefetz A., Cerdá X., Devers S., Francke W., Twele R. and Lenoir A. 2007c. Production of sexuals in a fission-performing ant: dual effects of queen pheromones and colony size. Behav. Ecol. Sociobiol. 61: 1531-1541

Boulay R., Carro F., Soriguer R. and Cerdá X. 2009a. Small-scale indirect effects determine the outcome of a tripartite plantdisperser-granivore interaction. Oecologia 161: 529-537

Boulay R., Cerdá X., Fertin A., Ichinose K. and Lenoir A. 2009b. Brood development into sexual females depends on the presence of a queen but not on temperature in an ant dispersing by colony fission, Aphaenogaster senilis. Ecol. Entomol. 34: 595-602

Brew C.R., O'Dowd D.J. and Rae I.D. 1989. Seed dispersal by ants: behaviour-releasing compounds in elaiosomes. Oecologia 80: 490-497

Bronstein J.L. 1994. Our current understanding of mutualism. Q. Rev. Biol. 69: 31-51

Caut S., Barroso A., Amor F. Cerdá X. and Boulay R. in press. A year in an ant's life: opportunism and seasonal variation in the foraging ecology of Aphaenogaster senilis Ecoscience

Cerdá X., Angulo E., Boulay R. and Lenoir A. 2009. Individual and collective foraging decisions: a field study of worker recruitment in the gypsy ant Aphaenogaster senilis. Behav. Ecol. Sociobiol. 63: $551-562$

Christianini A.V., Mayhé-Nunes A.J. and Oliveira P.S. 2007. The role of ants in the removal of non-myrmecochorous diaspores and seed germination in a Neotropical savanna. J. Trop. Ecol. 23: 343-351

Christianini A.V. and Oliveira P.S. 2009. The relevance of ants as seed rescuers of a primarily bird-dispersed tree in the Neotropical cerrado savanna. Oecologia 160: 735-745

Christianin V. and Oliveira P.S. 2010. Birds and ants provide complementary seed dispersal in a neotropical savanna J. Ecol. 98: $573-582$

Debussche M., Cortez J. and Rimbault I. 1987. Variation in fleshy fruit composition in the Mediterranean region: the importance of ripening season, life-form, fruit type and geo-graphical distribution. Oikos 49: 244-252

Eisner T. 1957. A comparative morphological study of the proventriculus of ants (Hymenoptera: Formicidae). Bull. Mus. Comp. Zool. Harv. Coll. 116: 439-490

Espadaler X. and Gómez C. 1996. Seed production, predation and dispersal in the Mediterranean myrmecochore Euphorbia characias (Euphorbiaceae). Ecography 19: 7-15

Espadaler X. and Gómez C. 1997. Soil surface searching and transport of Euphorbia characias seeds by ants. Acta Oecol. 18: 39-46

Fenner M. and Thompson K. 2004. The Ecology of Seeds. Cambridge University Press, Cambridge

Fischer R.C., Ölzant S.M., Wanek W. and Mayer V. 2005. The fate of Corydalis cava elaiosomes within an ant colony of Myrmica rubra: elaiosomes are preferentially fed to larvae. Insect. Soc. 52: 55-62

Fischer R.C., Richter A., Hadacek F. and Mayer V. 2008. Chemical differences between seeds and elaiosomes indicate an adaptation to nutritional needs of ants Oecologia 155: 539-547
Fokuhl G., Heinze J. and Poschlod P. 2007. Colony growth in Myrmica rubra with supplementation of myrmecochorous seeds Ecol. Res. 22: $845-847$

Fokuhl G., Heinze J. and Poschlod P. 2012. Myrmecochory by small ants - Beneficial effects through elaiosome nutrition and seed dispersal. Acta Oecol. 38: 71-76

Fourcassié V. and Oliveira P.S. 2002. Foraging ecology of the giant Amazonian ant Dinoponera gigantea (Hymenoptera, Formicidae, Ponerinae): activity schedule, diet and spatial foraging patterns. J. Nat. Hist. 18: 2211-2227

Gammans N., Bullock J.M. and Schönrogge K. 2005. Ant benefits in a seed dispersal mutualism. Oecologia 146: 43-49

Giladi I. 2006. Choosing benefits or partners: a review of the evidence for the evolution of myrmecochory. Oikos 112: 481-492

Gorb E. and Gorb S. 2003. Seed Dispersal by Ants in a Deciduous Forest Ecosystem. Kluwer, Dordrecht

Gove A.D., Majer J.D. and Dunn R.R. 2007. A keystone ant species promotes seed dispersal in a "diffuse" mutualism. Oecologia 153: $687-697$

Grooms L. 2006. The pros and cons of TZ testing. Seed Today 10 58-60

Heithaus E.R. 1981. Seed predation by rodents on 3 ant-dispersed plants. Ecology 62: 136-145

Herrera C.M. 1989. Frugivory and seed dispersal by carnivorous mammals and associated fruit characteristics, in undisturbed Mediterranean habitats. Oikos 55: 250-262

Herrera C.M. 1995. Plant-vertebrate seed dispersal systems in the Mediterranean: ecological, evolutionary, and historical determinants. Annu. Rev. Ecol. Syst. 26: 705-727

Herrera C.M. 2001. Dispersión de semillas por animales en el Mediterráneo: ecología y evolución. In: Ecosistemas mediterráneos. Análisis funcional (Zamora R. and Pugnaire F.I., Eds). CSIC - Asociación Española de Ecología. Madrid, Spain, pp 125-152

Herrera C.M. 2002. Seed dispersal by vertebrates. In: Plant-Animal Interactions (Herrera C.M. and Pellmyr O., Eds). Blackwell, Oxford, pp 185-208

Horvitz C.C. and Schemske D.W. 1986. Seed dispersal of a Neotropical myrmecochore: variation in removal rates and dispersal distance. Biotropica 18: 319-323

Hughes L. and Westoby M. 1992. Fate of seeds adapted for dispersal by ants in Australian sclerophyll vegetation. Ecology 73: 12851299

Hughes L., Westoby M. and Jurado E. 1994. Convergence of elaiosomes and insect prey: evidence from ant foraging behavior and fatty acid composition. Funct. Ecol. 8: 358-365

Hulme P. 1997. Post-dispersal seed predation and the establishment of vertebrate dispersed plants in Mediterranean scrublands. Oecologia 111: 91-98

Janzen D.H. 1983. Seed and pollen dispersal by animals: convergence in the ecology of contamination and sloppy harvest. Biol. J. Linn. Soc. 20: $103-113$

Jordano P. 1989. Pre-dispersal biology of Pistacia lentiscus (Anacardiaceae): cumulative effects on seeds removal by birds. Oikos $\mathbf{5 5}$ : 375-386

Jordano P. 1995. Angiosperm fleshy fruits and seed dispersers: a comparative analysis of adaptation and constraints in plantanimal interactions. Am. Nat. 145: 163-191

Lubertazzi D., Lubertazzi M.A.A., McCoy N., Gove A.D., Majer J.D. and Dunn R.R. 2010. The ecology of a keystone seed disperser, the ant Rhytidoponera violacea. J. Insect. Sc. 10: 158

Manzaneda A.J., Rey P. and Boulay R. 2007. Geographic and temporal variations in the ant-seed dispersal assemblage of the perennial herb Helleborus foetidus. Biol. J. Linn. Soc. 92: 135-150

Manzaneda A.J. and Rey P.J. 2012. Geographical and interspecific variation and the nutrient-enrichment hypothesis as an adaptive advantage of myrmecochory. Ecography 35: 322-332 
Marussich W.A. 2006. Testing myrmecochory from the ant's perspective: The effects of Datura wrightii and D. discolor on queen survival and brood production in Pogonomyrmex californicus. Insect. Soc. 53: 403-411

McKey D. 1975. The ecology of coevolved seed dispersal systems. In: Coevolution of Animals and Plants (Gilbert L.E. and Raven P.H., Eds). University of Texas Press, Austin, USA. pp 159-191

Méndez M. and Díaz A. 2001. Flowering dynamics in Arum italicum (Araceae): relative role of inflorescence traits, flowering synchrony, and pollination context on fruit initiation Am. J. Bot. 88: 1774-1780

Morales M.A. and Heithaus E.R. 1998. Food from seed-dispersal mutualism shifts sex ratios in colonies of the ant Aphaenogaster rudis. Ecology 79: 734-739

Ness J.H., Morin D.F. and Giladi I. 2009. Uncommon specialization in a mutualism between a temperate herbaceous plant guild and an ant: are Aphaenogaster ants keystone mutualists? Oikos 118: 1793-1804

Passos L. and Oliveira P.S. 2004. Interaction between ants and fruits of Guapira opposita (Nyctaginaceae) in a Brazilian sandy plain rainforest: ant effects on seeds and seedlings. Oecologia 139: 376-382

Pfeiffer M., Huttenlocher H. and Ayasse M. 2010. Myrmecochorous plants use chemical mimicry to cheat seed-dispersing ants. Funct. Ecol. 24: 545-555
Pizo M.A. and Oliveira P.S. 1998. Interactions between ants and seeds of a non-myrmecochorous neotropical tree, Cabralea canjerana (Meliaceae), in the atlantic forest of southeast Brazil. Am. J. Bot. 85: $669-674$

Pizo M.A. and Oliveira P.S. 2000. The use of fruits and seeds by ants in the Atlantic forest of southeast Brazil. Biotropica 32: 851-861

R Development Core Team 2010. R: A language and environment for statistical computing. R Foundation for Statistical Computing, Vienna, Austria. URL http://www.R-project.org/

Roberts J.T. and Heithaus E.R. 1986. Ants rearrange the vertebrategenerated seed shadow of a neotropical fig tree. Ecology 67: 1046-1051

Snow D.W. 1971. Evolutionary aspects of fruit-eating by birds. Ibis 113: $194-202$

Traveset A. 1994. Cumulative effects on the reproductive output of Pistacia terebinthus (Anacardiaceae). Oikos 71: 152-162

Wang B.C. and Smith T.B. 2002. Closing the seed dispersal loop. Trends Ecol. Evol. 17: 379-385

Wheelwright N.T. and Orians G.H. 1982. Seed dispersal by animals: contrasts with pollen dispersal, problems of terminology, and constraints on coevolution. Am. Nat. 119: 4020-413

Zelikova T.J., Dunn R.R. and Sanders N.J. 2008. Variation in seed dispersal along an elevational gradient in Great Smoky Mountains National Park. Acta Oecol. 34: 155-162 